New Zealand journal of industrial relations, 1988, 13, 237-255

\title{
Equal pay for work of equal value - job evaluation issues
}

\author{
Prue Hyman *
}

\section{Introduction}

Equal pay is again an issue on the political and industrial relations scene, as it has been in each recent decade despite a few quiet years. The current campaign is for legislation to amend or replace the 1972 Equal Pay Act to clearly incorporate the principle of equal pay for work of equal value ('comparable worth' or 'pay equity' in North American parlance). While the Act appears to extend well beyond equal pay for identical work to allow comparisons on the basis of skills, effort, responsibility and conditions, there is considerable doubt that it was ever applied in this way, and the Arbitration Court judgement in the 1986 Clerical Workers case (A.C. 24/86 D.I. 176/85) means that for all practical purposes this is now impossible.

The female/male average earnings ratio narrowed during the equal pay implementation period by some 6 to 7 percentage points. (For ordinary time hourly earnings, which give the narrowest gap since they are unaffected by women's lower average working hours, the ratio went from 72.1 percent to 78.5 percent between 1972 and 1977). It has remained about the same since that time. There is, of course, room for considerable disagreement over the nature and magnitude of the factors responsible for the gap and the proportion which can be regarded as justified by non-discriminatory factors. However, the comparatively small effect of the legislation, at least compared to Australia, which is the most similar country to New Zealand with respect to pay-fixing arrangements and equal pay mechanisms, is a major factor driving the new campaign. In Australia, figures for hourly earnings with a broadly comparable coverage show a narrowing of about 12 percentage points, from 76 percent in 1972 to 88 percent in 1978, largely as a result of the Arbitration Commission's rulings (O'Donnell and Hall, 1988, p.50).

The Government response to pressure for a review of the Act was to commission in 1986 a study of the earnings gap and the factors accounting for it. Phase One of this study was completed during 1987, and the report and references therein should be consulted for detailed discussion of the matters touched on so far (Urban Research Associates et al, 1987). Phase Two, also completed in 1987, consisted mainly of an outline of legislative provisions in various overseas jursidictions. It also discussed briefly the links between equal pay and equal opportunity policies in any attempt to narrow the male-female earnings gap and recommended that Phase Three should suggest what changes were 
earnings gap and recommended that Phase Three should suggest what changes were necessary to policies and/or legislation in both fields. Finally, it supported the development of gender-free job evaluation systems as part of the Phase Three exercise. Phase Three was effectively transformed into the Working Group on Equal Employment Opportunities and Equal Pay, operative between March and June 1988 and reporting to the Cabinet Social Equity Committee. The Group's report, Towards employment equity, (Working Group, 1988) recommends new legislation covering both equal opportunity (for Maori and other ethnic groups and people with disabilities, as well as women) and equal pay for work of equal value.

The degree of Government commitment to legislation in this area is uncertain. Ministerial speeches and party documents have varied in their degree of specificity with regard to new legislation as opposed to general support for elimination of discrimination. The recommendations of the Working Group Report have received no Cabinet endorsement, though the Prime Minister, his Deputy and the Minister of Women's Affairs have indicated support. Submissions were to be made by the end of October 1988, and Labour Department and Working Party reports on them will be available to Cabinet before the end of 1988.

Legislative initiatives with regard to equal pay for work of equal value (as against equal opportunity, which is less controversial) do not sit easily with the general tenor of government moves towards greater flexibility in the labour market. However, if the contention of the advocates - that the market discriminates against female dominated occupations - is accepted or allowed to be tested under new legislation, then movement in these two apparently contradictory directions may in fact proceed simultaneously. Efficiency, as well as equity, arguments can be made in favour of intervention if it is accepted that there are areas where women's returns to human capital acquisition are less than men's (see Buchele and Aldrich, 1985).

It is clear that any attempt to implement equal pay for work of equal value depends on the use of a system or systems of job evaluation. The Working Group's recommendations hinge on comparisons of work between female and male occupational classes, conducted through the use of a gender-neutral job evaluation scheme based on stated criteria. Hence the purpose of the remainder of this paper is to consider in more detail than previous New Zealand discussions the links between job evaluation and equal value concepts. A discussion of general issues is followed by an examination of schemes used by two particular firms of consultants, Hay and Price Waterhouse.

\section{Job evaluation - general considerations}

There are many slightly different definitions of job evaluation, some taking its scope to go only as far as the provision of a ranking or points score for different jobs, while others see it also covering the process of converting this to a salary structure. One general (G.B.) definition/discussion is as follows:

Job evaluation is a system of comparing different jobs to provide a basis for a grading and pay structure. The aim is to evaluate the job, not the job holder, but it is recognised that to some extent any assessment of a job's total demands relative to another will always be subjective. Moreover, job evaluation is in large part a social mechanism which establishes agreed differentials within organisations. (Equal Opportunities Commission, 1985, p. 1).

The analysis here will disregard the somewhat primitive job evaluation schemes which are non-analytical, assessing whole jobs rather than subdividing the jobs into relevant 
components. Thus it will concentrate on factor point analytical methods. These methods define factors which are important to the jobs and therefore appear to be a legitimate basis for differences in pay. They then score each job on each factor and add the scores (or weight them in some more complex manner) to give a combined total score. Two jobs do not need to be rated identically on each factor to be judged of equal value. Jobs which have the same (or in some cases very close) aggregate scores are deemed to be of equal value.

Parts of the discussion which follows draw heavily on the Phase One Report of the Equal Pay Study, of which I was co-author. It will be helpful to start with a description summarising the main issue in job evaluation.

The worth of any given job would be computed as a weighted sum of the
scores it receives for its working conditions and its skill, effort and
responsibility requirements. Two jobs would be deemed comparable if one
job's worth, calculated in the manner just described, is the same as (or within
a few points of the other job's worth. In a superficial sense, the job
evaluations that would be used in determining the worth of different jobs
would therefore be similar to those currently used by employers. However,
there is one crucial difference between the kind of job evaluation that would
be used with comparable worth policies and that typically used by employers:
the latter are typically based explicitly on market considerations. For
example, commercial job evaluation firms often benchmark wages for key
jobs on the basis of labour market surveys and use procedures such as
regression analysis of existing salary structures to determine the weights that
the marketplace itself gives to the different factors considered. In contrast,
some analysts of comparable worth question such a market-oriented approach
on the grounds that the wage relationships that currently exist are likely to
be distorted by discrimination. Some comparable worth proponents advocate
the use of bias-free job evaluations, i.e., ones that are derived independently
of the existing wage structure and in which the weights given to the different
factors considered would be determined on an a priori - or to put it less
charitably, ad hoc - basis. (Killingsworth in Hartmann, (ed), 1985, p. 87).

As mentioned in the above extract, the contention of comparable worth advocates is that current wage relationships are distorted by discrimination. In particular, it is argued that the skills needed in many female-dominated occupations are undervalued due to the fact that, for historical and social reasons and because experience rather than formal training courses may have been involved in their acquisition, they are seen as extensions to women's work in the home and to their traditional caring roles. An Australian dicussion explains how this has led to the perpetuation of low pay for women from work value comparisons:

The weighting which has traditionally been assigned to the various factors has led to a high importance being placed on aspects of work which are characteristics of male occupations, e.g. bad working conditions, manual labour and responsibility for plant and machinery. Also skills are usually measured by formal apprenticeship or technical training and these programmes have mainly been instituted in industries which are male dominated...

Male classifications

Salesman

Assistant Manager

Technician

Office Manager

Personal Assistant
Female classifications

Shop assistant

Manager's assistant

Operator

Typing Supervisor

Secretary 
A cursory glance at this list of male dominated classifications illustrates how these jobs are accorded more prestige than the female dominated classifications. They are jobs with a future, jobs which carry more authority and jobs which imply more skill. This is despite the fact that in many cases the duties, responsibilities, skills and training involved in the jobs are the same whether classified as "men's work" or "women's work" - a female shop assistant in the handbag department of a large retail store performs essentially the same work as a salesman in an electrical goods store, yet their relative earnings are unlikely to reflect this equality.

Where does this disparity come from? Why should the physical strength involved in many men's jobs, e.g. labourer, be valued more highly than the manual dexterity involved in many women's jobs, e.g. typist? Why should responsibility for machinery, e.g. mechanic, be considered more valuable than responsibility for people, e.g. nurses?

It is curious that where women perform work which has been deemed to involve abilities "natural" to women these abilities have been devalued and jobs requiring such abilities have been deemed unskilled.

The assumption that qualities such as caring and nurturing occur naturally to women means that the job of nursing may conveniently be assumed to be one which does not require much acquired skill. Since the job does not then involve "skills" it may be undervalued and the effect of this undervaluation is low pay. This pattern may be seen to operate in many traditional "women's jobs," from the undervalued "natural" manual dexterity of female process workers to the undervalued "natural" conscientiousness of female cleaners. The idea that the skills involved in women's work are inherently inferior is deeply entrenched. (Women's Legal Resources Group, 1985).

A study of the U.S. Department of Labour's Dictionary of Occupational Titles, which rates jobs in terms of a skill-complexity code, showed that

...evaluators had overlooked important characteristics of female-dominated jobs, especially those associated with taking care of children. The evaluators did not regard these as job related skills, but rather as qualities intrinsic to being a woman. Because of this, the job evaluators were confusing the content and responsibilities of a paid job with stereotypic notions about the characteristics of the job-holder. (Steinberg and Haignere, 1985, p. 13).

A further problem which arises in the use of job evaluation is that of inaccurate or incomplete job descriptions. While self reporting of job content is to be encouraged for obtaining cooperation and confidence in the process and to avoid the biases of supervisors' inaccurate perceptions, there is considerable evidence of the tendency for women to underdescribe and men to overdescribe their jobs (op. cit. p. 14 and Remick, 1979). "Halo" effects can also occur, where pre existing notions on the value of jobs or of particular features of such jobs, often based on their current market valuation, colour the view of what they must involve with respect to other factors and thus perpetuate their inflation or under-valuation (see Tables 1, 2 and 3, appended).

It should be noted that the question of possible revaluation of jobs is not entirely a matter of female-dominated occupations. Historical differentials, to the extent that they are based on analyses and decisions on skill levels, have been challenged in other ways. Similar arguments are being made in the United States with respect to pay differences by race and, more generally, it is asserted that skill definition and assessment is very largely a social construct. There is a growing literature on skill analysis which supports this view (see, for example, Cockburn, 1983, Hill and Novitz, 1985 and Wood, 1986). 
Another general problem with job evaluation systems is one which occurs with any system of combining separate scores. Proposed weightings of different factors will fail to be reflected in realised weightings if the variation in the scores between different jobs is more for some factors than others. Also, the tendency to use overlapping or related factors for which job scores are highly correlated means that greater weight may be attached to a group of factors than intended (on these points see Gill and Ungerson, 1984, p. 44/53).

It is clear from the discussion that searching for absolute objectivity in job evaluation is a mistaken approach. However, job evaluation makes explicit and open for discussion the judgements which may otherwise be only implicit. A variety of evaluations and studies, even though they may differ in detail, have almost invariably found that femaledominated occupations are underpaid - and some critics consider that the extent of this result has been understated in studies which have failed to avoid all the biases mentioned above (Treiman and Hartmann, 1981 and Wisconsin Task Force, 1985).

Opponents of the broadening of the concept of equal pay for work of equal value point to the lack of consistency in ranking and scoring of jobs between different studies (Burr, 1986). The other major argument put forward is that the market should be the main factor in pay determination. It thus follows that evaluation should only be used to reproduce or justify the current pay structure, or minor amendments to it, and slot in new jobs. Thus job evaluation schemes and current market valuations become mutually reinforcing. The contrast between the ad hoc and market approaches to job evaluation is clearly put in the Killingsworth quotation above.

In the American literature, these two approaches are often known as a priori and 'policy capturing'. Both have been used in American studies related to comparable worth. A leading study describes the latter approach as follows:

This involves developing a compensation model in which specific job content features needed to perform the job are divided into factors and then these factors are weighted in such a way that they statistically "predict" the current wage structure. In other words, the weights for each compensable job content characteristic are derived from a statistical model which makes explicit what is currently implicitly valued for compensation purposes within an organisation. (Steinberg, R et al, 1986, p.9/10).

It might be seen as somewhat surprising that this approach has been used in comparable worth studies since:

it does not tell an employer what job content should be valued. It requires only that whatever an employer values is valued consistently and systematically across all job titles and not arbitrarily and implicitly as a function of the sex or race/ethnicity of the typical incumbent of a job title (op. cit., p. II).

Thus an approach to eliminating pay inequities revealed by such a study will probably capture only part of what equal value advocates see as discriminatory. If women are paid less than men after standardising for pay differences due to all relevant job factors, this can be labelled as direct discrimination (assuming it is not related to assessment of job performance separate from evaluation of the actual job - over a large sample this should not be relevant). However, low (or negative) valuation of factors particularly prevalent in female dominated occupations is not regarded as discriminatory in this quotation. These valuations will, however, be revealed by such a study and so arguments could still be advanced that they are inappropriate.

In using such a study to estimate and possibly correct for the degree of underpayment (and, if desired, overpayment) of particular occupations, a number of approaches are possible. Three "pay policy regression lines" are usually estimated. The first is based on 
all jobs and thus reproduces the current pay structure, apart from random error. The second adjusts the first to remove statistically any effect of underpayment of female - and if relevant, minority - dominated occupations, after standardising for all other factors. Thus for any particular job, values for the characteristics included can be inserted in the equation to produce a theoretical salary or grade which can be compared with the actual. The third line is similar, except it is based on only those jobs thought to be free of discrimination in the pay structure - male dominated jobs (with an appropriate percentage definition) or often white male jobs in a U.S. context.

Which pay policy line is used for revaluation of jobs and adjustment of salaries is clearly crucial in terms of the individual changes and overall cost. While in principle some jobs could be adjusted downwards, this is frequently a political impossibility, so limiting the scope of the adjustment and using a phase-in period are common ways of limiting and/or cushioning the cost. Regression analysis is also used in the a priori approach. A simple example showing two regression lines relating pay levels in predominantly male and female jobs to job worth points is given in table 3 . It refers to a study of the Washington State public service and shows that male dominated jobs are paid a higher base level and more per job point than female dominated jobs.

Full understanding of the policy capturing approach will be assisted by discussion of a particular case. The New York State pay equity study used a very detailed self-completed job content questionnaire to sample job characteristics and grading/pay levels for State employees. A high response rate sample of 25,852 usable questionnaires covering 2,582 job titles (from a total of 175,000 employees in 7,350 titles) was gathered in 1985 . Eighty job content items were factor analysed, with 14 factors emerging as important. These, together with some individual items, were entered as the independent variables in regression equations predicting the salary grade of different job titles. The independent variables also included dummy variables for occupations being female dominated and minority dominated (defined as 67.2 percent or more for the first, 30.8 percent or more for the second - based on 40 percent above the average level of each in the New York State labour force). Fifteen out of 27 variables were found to be significant in both the first two pay policy lines outlined above, accounting for nearly 90 percent of the variance in salary grade across jobs. The authors' summary includes the following:

Our results demonstrate that, for all pay policy lines, education, experience, management, supervision and writing are highly compensated factors in New York State government employment. Moreover, several factors are not valued or are negatively valued. These include unfavourable working conditions, stress, group facilitation, communication with the public, data entry, and autonomy. While the pay equity estimates are based on the obtained regression equations, New York State could explicitly choose to change any of the regression weights in order to value these job factors differently. ... Using the adjusted pay policy line, with all other job factors held constant, jobs done entirely by women are on average two salary grades lower than jobs of equal value to the state done entirely by men [my italics]. An increase of one salary grade is an increase of approximately five percent in salary. In order to calculate accurate predicted salary grades, we used a statistical procedure known as jackknifing. The estimated pay equity adjustments average 1.6 salary grades for the adjusted pay policy line and approximately 2.9 salary grades for the white male pay policy line. There is a strong tendency for job titles in the lower salary grades to be more undervalued than job titles in higher salary grades. Particularly among the clerical and health care system job titles it was common to find titles in grade levels 6 and below to be undervalued by four or five salary grades. (Steinberg et al 1986, p viii). 
The factor analysis and fitted equations show that the education and experience variables are the most important determinants of salary grade, accounting together for nearly 81 percent of the total variance (op. cit. p. 154). The point about which job factors are valued in the New York State system, which I have italicised above, needs further emphasis. The more detailed report includes the following extracts:

It is instructive to note what New York State does not pay for as well as what it does pay for. By and large, the coefficients have the expected sign... In one case the coefficient was not in the predicted direction. That exception is unfavourable working conditions. Communication with the public is also negatively valued. Some additional factors and items had no net impact at all on salary grade. Jobs in New York State requiring contact with difficult clients and jobs involving stress are neither rewarded nor penalized relative to other jobs with similar requirements in all other respects (op. cit., p.160).

\section{They go on to comment:}

One question that must be addressed in the review of this report is whether the job content characteristics found to be negatively valued or of no value are differentially associated with female-dominated or disporportionately minority job titles. If this is the case, there may be bias in the current compensation model for New York State. For example, contact with difficult clients and data entry are content characteristics associated with disproportionately female and minority institutional and clerical jobs. They currently are not valuable job content characteristics for pay purposes (op. cit., p. 160).

The possible revaluation of characteristics from this point of view has not occurred in New York. Only the more minor changes associated with the lower pay of women even within the current system of valuing job characteristics were proceeded with. The senior author of the study later commented:

The New York State study did not correct for the gender and race bias in its compensation policies. ... We were not allowed to correct the model in predicting unbiased salary estimates.... Having proven to myself and to others that a rigorous and sophisticated study of wage discrimination would be completed, the results were deeply disturbing to me... I will only conduct research when such studies carry the potential of moving pay equity more in the direction of the original standards of eliminating discrimination. Thus I am working on a study of Philadelphia which involves cleansing their existing job evaluation system of gender and race bias in the definition of factors and factor weights. It not only provides me with an opportunity to eliminate inconsistencies in the wage structure but will also allow me to correct the negative wage effects of the "femaleness" and "minorityness" of a job (Steinberg, 1987, p. 15/20).

\section{Job evaluation - particular examples}

It will be helpful in fleshing out the general discussion above to consider briefly two particular job evaluation systems, those of two firms of management consultants, Hay and Price Waterhouse. These, like any systems applied to a number of organisations, are $a$ priori schemes in the terminology discussed above, although they have, of course, been developed and refined over years of use. Hay, in particular, has had in North America to meet the challenge of comparable worth. As a paper contributed by the firm to a New Zealand seminar states: 
Undoubtedly Hay Management Consultants is no stranger to job evaluation. It is currently the most widely used system of job evaluation throughout the world, and has been used far more frequently than any other system in situations calling for the investigation of equality of pay for work of comparable value. But even the Hay system has had to undergo changes in order to satisfy the evolving equal pay environment overseas (Hay Management Consultants, 1986, p.4).

The paper went on to outline the Hay system, in which the major factors are knowhow $(\mathrm{K})$, problem solving $(\mathrm{P})$ and accountability $(\mathrm{A})$, each subdivided into more detailed factors in a grid system. The total score is $\mathrm{K}+(\mathrm{P} \%$ of $\mathrm{K})+\mathrm{A}$. Under equal value legislation employers are required to compare all jobs within their organisation in terms of defined factors:

This means that regardless of differences in job content, the Typist's job would be compared to that of the Inventory Control Clerk, the Secretary to the Machine Operator, the Senior Laboratory Technician to the Junior Engineer, and a Telephone Receptionist to a Truck Driver (op. cit., p. 1).

The examination and changes Hay had to make to meet the equal pay environment were discussed, in part, as follows:

Hay re-examined its system to ensure it contained no apparent biases. As a result of this examination, several problems were identified. For instance, Hay found that its system had not recognised the accountability associated with lower level jobs. Nor had it given the proper weighting to mental effort when assessing the nature of working conditions (op. cit., p. 5).

The paper pointed out other factors affecting individual salaries:

Job evaluation is the process of determining job size and is the basis for establishing a salary range around the job, not for determining individual salaries. Individuals may be assigned different salary rates within the range based on criteria such as differences in performance, years of service and the like. It is usually agreed that a difference of salary is not discriminatory if it is based on a merit pay system that is free of bias and equally applied to all employees (op. cit., p.4).

The Hay paper takes strongly the view that comparisons must be within the workforce of a single employer, which is also the standard view of most employers and employers' organisations.

The process of a comparison is only applicable within organisations, or to groups of employees of the same employer. Clearly, we do not find in any marketplace analysis that all employers in a given industry will pay to the same marketplace level (op. cit., p. 4).

This is a controversial viewpoint which will be discussed later in this paper.

The contention that the Hay system is now bias free is not accepted by all parties:

The distribution of points among job factors may result in a weighting system oriented to job characteristics predominating in white male jobs. For instance, managing money or responsibility for heavy equipment frequently receives a higher percentage of overall points than responsibility for clients and human relations skills. In the Hay Guide-Chart System, one set of charts 
is constructed so that the number of points in the "Managerial Know-How" scale is five times as great as the number of points in the "Human Relations Know-How" scale. On the same chart, "Technical Know-How" can receive seven times the number of points as "Human Relations Know-How." Human Relations skills are disproportionately found in women's and minorities' jobs. Fiscal responsibility and heavy machinery are disproportionately associated with white male jobs. As a result, the point values contained in the charts may reflect a traditional bias against the content of female and minority jobs (Steinberg and Haignere, 1985, p. 19/20).

Other criticisms of the system could be made. For example, the accountability criterion appears to be seen largely in financial terms, neglecting other aspects of possible importance. This is related to the fact that this and similar systems are developed largely for managerial type jobs and do not seem easily able to be adapted to other areas. Human relations skills are regarded as part of know-how and the need to excercise them can add on variable numbers of points, increasing with the scientific/ technical/practical skills and breadth of management know-how also needed in the job. This means that where scores on the latter are low, the need for human relations skills add little to the evaluation and in no case can they add as much as one third to the score provided by the other two elements of the know-how grid. The Hay system is, I understand, being used extensively in New Zealand, so that understanding of its methodology, assumptions and limitations is important. The State Services Commission have been users of the system, but are becoming aware of criticisms and are reviewing them and a number of other systems.

A version of the Price Waterhouse system, on the other hand, uses ten factors education (E), experience (X), complexity (C), scope of work (S), problem solving, supervision received, results of decisions, contacts, authority excercised, and supervisory/managerial responsibility. Complexity and scope are scored in percentage terms, while the remaining factors have a numerical score out of a maximum varying from 132 for contacts (with other personnel employed and/or the public) to 700 for problem solving and for results of decisions. The total score (T) is calculated as follows:

$\mathrm{T}=(\mathrm{E}+\mathrm{X})(\mathrm{C}+\mathrm{S})+\mathrm{E}+\mathrm{X}+\mathrm{F}$, where $\mathrm{F}$ is the sum of the scores on the six last factors listed.

As in the Hay case, questions arise as to the judgements involved in the varying maximum scores on the factors, the criteria in assigning scores and the method of weighting. Results of decisions and degree of authority excercised are evaluated entirely in financial terms. Education and experience enter the formula both directly and multiplied by the complexity/scope combined percentage assessment, so carrying major importance.

\section{Issues}

Schemes such as these, despite their reputations and extensive use, are thus not beyond criticism. The question of whether a single scheme can be devised for all jobs (at least within the compass of a single employer) is an important one. Clearly the policy capturing method allows for this. An a priori system which attempted to do the same would need to draw on the factors emerging from large cross occupation policy capturing studies.

A number of researchers studying the application of job evaluation to comparable worth have argued strongly for a single system: 
The goal of pay equity requires the elimination of multiple plan job evaluations within a firm or public jurisdiction... Comparable worth requires consistent treatment of all job titles in every component of job evaluation (Steinberg and Haignere, 1985, p. 12).

With multiple job plans, it is argued, different job content features used for job descriptions and different factor definitions, evaluations and weightings lead to inconsistencies and difficulty in making comparisons across categories. When different occupational categories, such as clerical, manual labour and managerial jobs are treated independently and show very different patterns of sex and race profiles, the type of biases discussed earlier can easily emerge.

It was mentioned earlier that employers usually argue for within employer comparisons only, as marketplace factors may account for differences between firms. In New Zealand, above award payments, for example, may differ between firms. The Equal Pay Act simply requires that these payments, as with the awards themselves, not be based on the sex of the employee. Most activity in the comparable worth area in the United States has been of this within employer type, particularly at the level of state and local government employers. A number of factors account for this. Wage setting mechanisms are less centralised and more a matter of negotiation with individual employers than is (yet) the case in New Zealand. Government is an easier target for political/pressure group action than private employers and more likely to feel some responsibility in the area of equal pay. Thus several state governments have instituted pay equity studies on the lines of the New York study discussed earlier and some have made pay settlements arising from (or even without) such studies. The legislation in Great Britain also relates to individual employers.

The Australian system of pay fixing and of equal pay implementation is more similar to that of New Zealand, although with some critical differences. The adoption there, in theory at least, of the principle of equal pay for work of equal value was due to a decision in 1972 of the Australian Conciliation and Arbitration Commission, requiring that female rates be determined by work value comparisons without regard to sex. They said:

The gap between the level of male and female rates in awards generally is greater than the gap, if any, in the comparative value of work performed by the two sexes because rates for female classifications in the same award have generally been fixed without a comparative evaluation of the work performed by males and females... Implementation of the new principle by arbitration will call for the exercise of the broad judgment which has characterised work value inquiries. Different criteria will continue to apply from case to case and may vary from one class of work to another. ... Work value comparisons should, where possible, be made between female and male classifications within the award under consideration. But where such comparisons are unavailable or inconclusive, as may be the case where the work is performed exclusively by females, it may be necessary to take into account comparisons of work value between female classifications within the award and/or comparisons of work value between female classifications in different awards. In some cases comparisons with male classifications in other awards may be necessary. (Orr, 1986a, pp 2-3 quotes the full principle, which is from judgement Print B8506; (1972) 147 CAR 172).

However, the Victoria Women's Legal Resources Group quoted earlier were unable to find evidence of any work value comparisons being carried out and a later case makes clear that only narrow comparisons were intended. The Commission then stated:

The 1972 decision requires equal pay for work of equal value to be implemented in all cases by means of work value enquiries. This limits the 
comparisons to "like work" in the normal manner in which work value enquiries were then and are still conducted in the wage fixing process in Australia (Australian Conciliation and Arbitration Commission, 1986, p. 9).

It appears therefore that the female-male earnings gap narrowed by an across the board process, rather than by any reappraisal of the value of female dominated work. This was probably assisted by the smaller disparity between male earnings in female dominated work and average male earnings in Australia than is the case, for example in Great Britain. (For a fuller treatment of this see Urban Research Associates, 1987, p. 22 and 43-44 and Gregory, Daly and Ho, 1986). This across the board process resulted in a considerably greater narrowing of the female-male earnings gap in Australia than occured in New Zealand. The 1972 New Zealand Equal Pay Act stated that in female dominated areas the rate of remuneration for females should be the rate "that would be paid to male employees with the same or substantially similar skills, responsibility and service, performing the work under the same or substantially similar degrees of effort" (Equal Pay Act, 1972, Section 3(l)b). This became known as the 'notional male rate', later changed to the "equal pay rate". The Act goes on to outline the equal pay determinations to be made where instruments contained any separate provision for female employees, or made provision for female employees only. This relies on job classification, but it is not clear which males (actual or theoretical) are to be comparators.

A Labour Department booklet issued in 1981 to explain the legislation and provide practical guidance for employers and employees states that:

if you are employing women in jobs that are often done mainly by women e.g. typing, waitressing, sewing, then you will need to relate these jobs to comparable male jobs in your establishment. ... Another approach you could take is to carry out an excercise to set a value on the jobs done by female employees in relation to a range of male jobs. This will allow you to determine an appropriate equal pay rate in a situation where men and women are doing quite different work (New Zealand Department of Labour, 1981).

How this was to fit with award systems of wage settlement was unclear. These statements are based on recommendations and comment in the 1979 Review of the legislation (Review Committee, 1979) and appear to encourage reasonably broad comparisons, albeit within the ambit of individual employers. However, from the limited evidence available it appears that only narrow comparisons were in fact made. Orr argues that it was inevitable for employers to look within their own industry for comparators, while guidelines published by the Employers Federation for their members in February 1973 suggested consultations to protect their interests and ways of implementing job classification which were as narrow as possible (and potentially discriminatory) (Orr, 1986b, p. 7/8).

\section{Possible changes to the New Zealand system}

It is hard to see how the policy capturing system of job evaluation could fit into a legislative framework for pay fixing/implementing equal pay for work of equal value in New Zealand. Nor are many single employers large enough for this. It would however be an interesting and useful excercise, if the data could be acquired, to examine the government workforce, that of a large local government unit and/or a large private firm in this way. Large units with a considerable variety of occupations provide the necessary setting for such assessment. 
If in practice $a$ priori evaluations are to be made within the current and evolving industrial relations/pay setting structure, a number of problems arise. In comparisons made only within awards or occupations covering a narrow range of jobs, the possible undervaluation of traditional female-dominated occupations cannot be addressed, particularly if male wages in such occupations are depressed to the low female level. Thus unions believe group or class comparisons must be permitted, across awards, occupations and employers - a process which is also more easily organised and less intimidating for the individual. There are investigations of possible structures and criteria under way. However, considerable employer resistance can be anticipated.

It should be reiterated that job evaluation systems must always embody value systems. In these circumstances, in the words of a U.S. study:

the adoption of any plan depends on its credibility with various groups in the workplace - the pay rates set for jobs must satisfy management, employees, and labor unions. Job evaluation plans instituted in organisations must thus satisfy perceptions of internal equity... Factors that are compensated need to be directly and demonstrably job-related. One implication is that successful implementation may require participation of all the various constituent groups... A growing number of firms have begun this process of developing job evaluation plans jointly through management and union negotiation, including $\mathrm{AT} \& \mathrm{~T}$ and the Communications Workers of America (Hartmann, Roos and Treiman, 1985 p. 16-17).

The book from which the above is extracted is devoted entirely to the research needed in the area of comparable worth, with a large section on job evaluation. Among the questions raised are the following:

\begin{abstract}
What criteria are used for identifying compensable factors for existing job evaluation systems?

Does consensus exist across workers (and management) as to what job factors should be compensated? Does this consensus vary by sex?

Are there potential compensable factors in women's work that are not now recognised as legitimate bases for pay differentials?

Do newly developed job evaluation systems tend to incorporate traditional values? To respond to current market conditions?

Are peoples' judgements about what salaries should be very different from actual salaries? How do peoples' judgements about deserved salaries evolve?

If tasks are identified as male or female are male tasks more highly valued?

Does adding female tasks (e.g. typing, nurturing, waiting on tables, clerical work) to job descriptions reduce the perceived value of a job?

Does the established consensus about the worth of tasks in jobs decline if the number of women entering the field increases?

Is there general societal consensus regarding which attributes of jobs ought to be compensated and regarding the relative importance of various attributes? If not, do workers and management value attributes of jobs differently? Do men and women value attributes of jobs differently?

What belief systems underlie the various job evaluation systems currently in use? How are these beliefs reflected in the compensable factors and weighting scheme of current systems? (op. cit., p. 11, 21, 29 and 30).
\end{abstract}

These questions need to be considered, rather than glossed over, in the ongoing debates on equal pay for work of equal value. They also need to be considered by firms developing and implementing job evaluation systems in conjunction with New Zealand enterprises, whether or not new legislation on equal value is introduced. The practical problems of implementing an agreed job evaluation scheme and avoiding biases at each stage of the 
process are also considerable, but there is now documented experience which can be used, for example for training purposes. (See for example an account of the use of and difficulties with the Hay system in an Australian College of Advanced Education reported in Burton, Hag and Thompson, 1987). Only if the lessons of such overseas exercises are learnt and embodied in procedures and practices adopted in New Zealand will equitable pay setting arrangements be realisable.

\section{Appendix - Tables}

Table 1: List of frequently overlooked job content in female jobs

-Fine motor movement skills like rapid finger dexterity

-Special body coordination or expert use of fingers and hands (e.g. typing, giving injections, sign painting)

-Scheduling appointments

-Coordinating meetings

-Record-keeping

-Filing

-Writing standard letters

-Reading forms

-Protecting confidentiality

-Working office machines

- Cleaning up after others

-Sitting for long periods of time

- Time stress

-Communication stress (dealing with upset people)

- gathering information from upset or ill people

- calming upset people

-Stress from distractions

-Stress from concentration (e.g. VDT)

-Stress from exposure to the sick and disabled with no hope of recovery

-Stress from multiple demands (receiving work from lots of people)

-Stress from multiple role demands (being asked to do work quickly and to provide better service to several people)

-Working with constant noise

-Working in an open office setting: with room dividers without room dividers

-Answering questions for the public on the phone or in person -Answering complaints from the public

-Responsibility for inmates, patients or residents of institutions

-Degree of severity of problems of inmates, patients or residents of institutions

-Degree to which new or unexpected problems on the job arise

-Damage to equipment from a mistake

Source: Steinberg and Haignere (1985) pp. 17-18 
Table 2: Job evaluation factors divided into categories Favours male jobs

\begin{tabular}{lll}
\hline & Strongly & Weakly \\
\hline Section 1 & -Length of service & $\cdot$ Age \\
Factors with a time & & $\cdot$ Qualifications \\
dimension & $\cdot$ Experience & $\cdot$ Education \\
& & $\cdot$ Knowledge \\
& & $\cdot$ Breadth of know-how \\
& & $\cdot$ Depth of know-how \\
\hline Section 2 & $\cdot$ Responsibility for \\
Factors with a & cash or assets \\
seniority dimension & &
\end{tabular}

Section 3

Factors with a

relationship

dimension

$\begin{array}{ll}\text { Section } 4 & \cdot \text { Heavy lifting } \\ \text { Factors with a } & \text {-Physical hazards } \\ \text { physical activity } & \text {-Spatial ability } \\ \text { dimension } & \text {-Unpleasant } \\ & \text { working conditions }\end{array}$

Section 5

Factors with a

mental activity

dimension

\section{- Technical expertise -Responsibility for equipment -Physical skills -Physical effort -Responsibility for product -Responsibility for standar - Operational knowledge -Knowledge of machinery, tools and materials -Numerical calculation -Knowledge -Numerical ability -Mathematical reasoning -Problem solving}

\footnotetext{
Section 6

-Differentiating sounds

Factors with a

sensory activity

dimension
}

Source: Equal Opportunities Commission (1985) pp.20-21 
Favours female jobs

\begin{tabular}{ccc} 
& Neutral & Weakly \\
\hline
\end{tabular}

-Training period

-Level of skill

-Confidential data/information

-Planning

-Discretion

-Responsibility

-Effect of decisions

-Supervision of subordinates

-Accountability

- Decision making

-Safety of others

-Co-operation

-Supervising

-Creating new business

-Communication

-Co-ordination

-Personal appearance

-Expression

-Safety of others

-Stamina

-Responsibility for materials

-Versatility

-Procedural know-how

-Contacts:internal/external $\cdot$ Caring

-Human relations

responsibility

-Public relations

responsibility

-Accuracy

-Fatigue

$\begin{array}{ll}\text {-Monotony } & \cdot \text { Dexterity } \\ \text {-Visual concentration } & \text {-Typing } \\ \text {-Scanning and location } & \text { and } \\ \text { of details } & \text { keyboard } \\ & \text { skills }\end{array}$

\begin{tabular}{|c|c|}
\hline $\begin{array}{l}\text {-Initiative } \\
\text {-Originality } \\
\text {-Ingenuity } \\
\text { - Judgement } \\
\text { - Mental effort } \\
\text {-Complexity of job } \\
\text {-Planning } \\
\text {-Verbal comprehension } \\
\text {-Verbal expression } \\
\end{array}$ & $\begin{array}{l}\text { - Concentration } \\
\text {-Memory } \\
\text {-Information ordering }\end{array}$ \\
\hline $\begin{array}{l}\text { - Differentiating tastes } \\
\text { - Differentiating smells } \\
\text { - Visual concentration } \\
\text { - Aesthetic appreciation } \\
\text {-Tactile sensitivity } \\
\text { - Artistic/Musical creativity }\end{array}$ & \\
\hline
\end{tabular}


Table 3: Scatterplot of monthly salaries by job worth points, for 59 jobs held mainly by men and 62 jobs held mainly by women in the Washington State public service.

o, For jobs held mainly by men $\ddot{Y}=1.87(X)+473$

- For jobs held mainly by women $\ddot{Y}=1.40(X)+393$

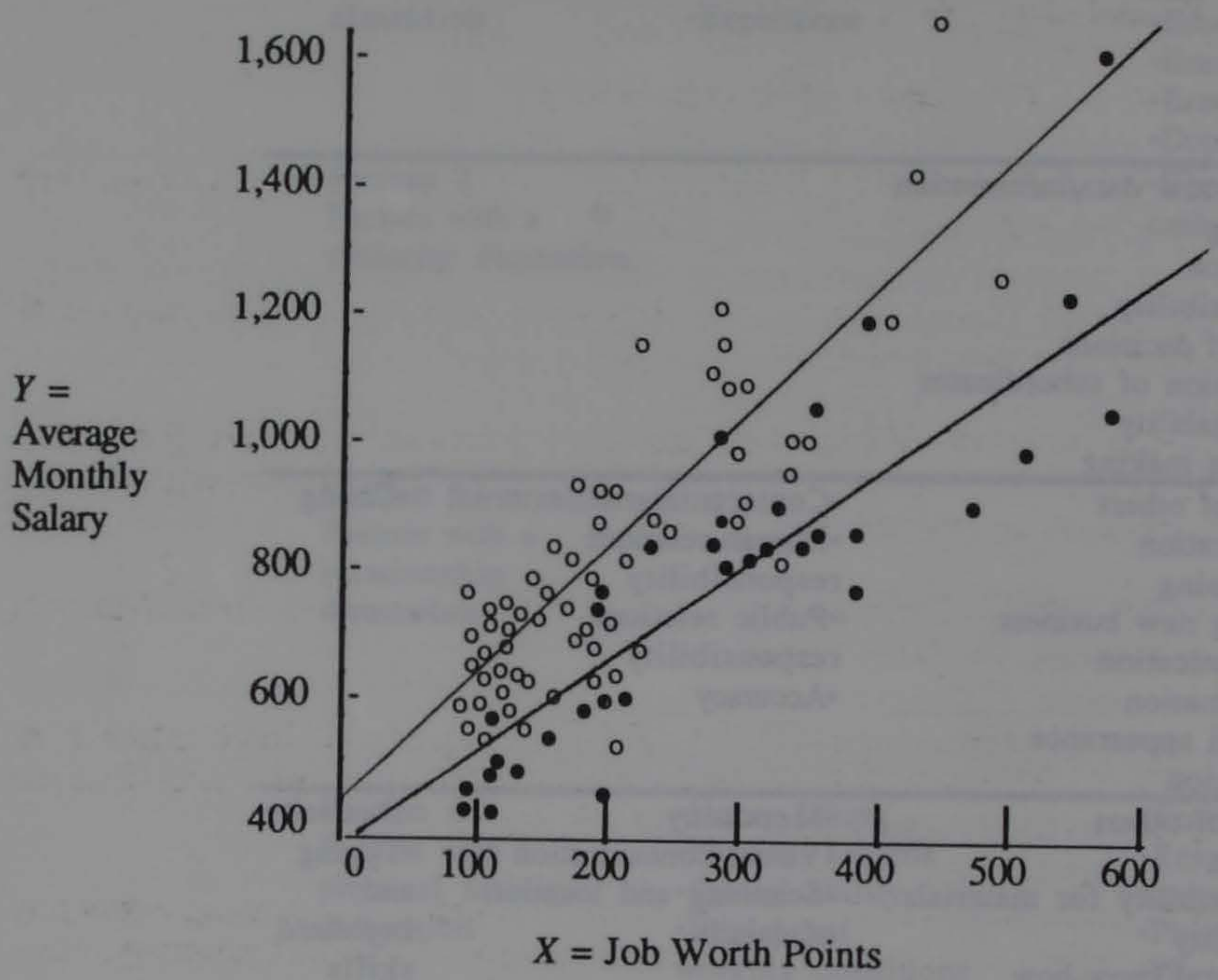

Source: Treiman and Hartman (eds) (1981) p. 61.

\section{References}

Arbitration Court (1986) Oral decision of the Court delivered by Finnigan, J (A.C. 24/86 D.I. 176/85), February, New Zealand.

Australian Conciliation and Arbitration Commission (1986) Judgement by Mr Justice Madden, President PO55CR MiS. 067/86MD Print G 2250, Australia.

Bergmann, B (1985) The economic case for comparable worth. In Hartmann, H I (ed) (1985) Comparable worth: new directions for research National Academy Press, Washington, United States.

Buchele, R and Aldrich, M, (1985) How much difference would comparable worth make? Industrial relations 24 (2) (Spring).

Burr, R (1986) Are comparable worth systems truly comparable? Center for the study of American business, Washington University, St. Louis, United States. 
Burton, C, with Hag, R and Thompson, G (1987) Women's worth - Pay equity and job evaluation in Australia AGPS Press, Canberra.

Cockburn, C (1983) Brothers - male dominance and technological change Pluto Press, United Kingdom.

Equal Opportunities Commission (1985) Job evaluation schemes free of sex bias Equal Opportunities Commission, United Kingdom.

Equal Pay Act 1972 No. 118 New Zealand Government.

Equal Pay Steering Committee (1987) Equal pay study phase two report Department of Labour, Wellington, New Zealand.

Gill, D and Ungerson, B (1984) Equal pay - the challenge of equal value Institute of Personnel Management, United Kingdom.

Gregory, R G, Daly, A and Ho, V (1986) A Tale of two countries: equal pay for women in Australia and Britain The Australian National University Centre for Economic Policy Research, Discussion Paper No. 147, August, Australia.

Hartmann, H I (ed) (1985) Comparable worth: new directions for research National Academy Press, Washington, United States.

Hartmann, H I, Roos, P A and Treiman, D J (1985) An agenda for basic research on comparable worth. In Hartmann, H I (ed) (1985) Comparable worth: new directions for research National Academy Press, Washington, United States.

Hay Management Consultants (1986) The role of job evaluation in promoting equal pay for work of equal value Centre for Continuing Education, Victoria University, New Zealand.

Hill, R and Novitz, R (1985) Class, gender and technological change Paper presented at annual conference of NZSA, (December) University of Waikato, Hamilton, New Zealand.

Hyman, P (1985) Equal pay for work of equal value - Is it a goal desirable, achievable, both or neither? In Women's Studies Association (NZ) conference papers New Zealand.

Hyman, P (1986) Perspectives on equal pay for work of equal value Centre for Continuing Education, Victoria University, New Zealand.

Iverson, S (1987) Why women get paid less Broadsheet Jan/Feb:38-40.

Killingsworth, M (1985) The economics of comparable worth: analytical, empirical and policy questions. In Hartmann, H I (ed) (1985) Comparable worth: new directions for research National Academy Press, Washington, United States.

Livernash, R E (ed) (1980) Comparable worth: issues and alternatives Equal Employment Advisory Council, United States. 
Llewelyn, L (1984) Setting wages according to comparable worth: An explanation and evaluation of alternative analyses UC Berkeley, United States.

New Zealand Department of Labour (1981) Equal pay New Zealand.

New Zealand Government (1986) Pay Fixing in the State Sector - A Review of Principles and Procedures in the Fixing of Pay and Associated Conditions in the New Zealand State Sector New Zealand.

NZFCA \& R Industrial Association of Workers (1986) Submissions to the Arbitration Court on Equal Pay and The Equal Pay Act 1972 New Zealand Clerical Workers Association, New Zealand.

O'Connell, T (1986) Political Lessons of Past Struggles in New Zealand and Australia Centre for Continuing Education, Victoria University, New Zealand.

O'Donnell, C and Hall, P (1988) Getting equal - labour market regulation and women's work Allen and Unwin, Sydney.

Orr, E W (1986a) The Arbitration Court's role in supervising the Equal Pay Act 1972 Centre for Continuing Education, Victoria University, New Zealand.

Orr, E W (1986b) The equal pay scene revisited Version 1, unpublished, New Zealand.

Remick, H (1979) Strategies for creating sound bias-free job evaluation systems. In Job evaluation and EEO: the emerging issues Industrial Relations Counselors Inc, New York:85-112.

Remick, H (ed) (1984) Comparable worth and wage discrimination Temple View Press, United States.

Review Committee appointed by the Minister of Labour (1979) Equal Pay Implementation in New Zealand Department of Labour, New Zealand.

Seligman, D (1984) Pay equity is a bad idea Fortune 14 May:89-96.

Steinberg, R J (1987) Dilemmas of advocacy research: experiences with comparable worth Paper to plenary panel of Social Science Research and Law Reform, Law and Society Association, United States, June.

Steinberg, R J and Haignere, L (1985) Equitable compensation: methodological criteria for comparable worth Paper for conference "Ingredients for women's employment policy", New York.

Steinberg, R J, Haignere, L, Possin, C, Chertos, C H and Treiman, D (1986) The New York State pay equity study: a research report New York.

Treiman, D J and Hartmann, H I (eds) (1981) Women, work and wages: equal pay for jobs of equal value National Academy Press, Washington D C.

Urban Research Associates, Hyman, P J and Clark, A (1987) Equal pay study phase one report Department of Labour, Wellington, New Zealand. 
Wilson, M (1986) An analysis of the present situation Centre for Continuing Education, Victoria University, New Zealand.

Wisconsin Task Force on Comparable Worth (1985) Report University of Wisconsin, United States.

Women's Legal Resources Group (1985) "She works hard for the money"... Equal pay for women Women's Legal Resources Group, Victoria, Australia.

Wood, S (1986) Work organisation. In Deem, R (ed) Work, culture and society Oxford University Press, United Kingdom.

Working Group on Equal Opportunities and Equal Pay (1988) Towards employment equity Wellington. 
The Journal of the Industrial Relations Society of Australia

Editor: Professor John Niland, The University of New South Wales

June 1988 - Volume 30 Number 2

Articles

Gender Differences in Union Attitudes, Participation and Priorities

John Benson and Gerry Griffin

Computer-Assisted Instruction in Industrial Relations

Teaching

R. E. Fells and J.R. Weaver

Shop Stewards' Image of Industrial Society and their Modes of Performance

Yonatan Reshef

The Law and Union Membership in US State and Local Government

Greg Hundley

Job Mobility in Australia: Theories, Evidence and

Implications

Thorsten Stromback

Information Theory and Employer Recruitment Practices

Margaret J. Nowak

Wages and On-Costs in Australian Industries: 1968-69 to $1985-86$

Peter B. Dixon, David A. Prentice and

Lynne S. Williams

Notes

Orientations to Work: A Comment

N. Dufty

Australian Strike Activity in an International Context, 1964-85: Comment

Richard Blandy

Australian Strike Activity in an International Context, 1964-85: Rejoinder

John J. Begg and Bruce J. Chapman

Book reviews

Published quarterly. Subscription: Australia $\$ 32$, overseas $\$ A 45$ (surface mail).

Single issues: $\$ A 9$ (including postage). Order from the

Business Manager, The Journal of Industrial Relations,

GPO Box 4479, Sydney, NSW 2001, Australia. 